\title{
An Analysis on Digital Watermarking in Videos based on Frequency Domain Techniques
}

\author{
Monasa Yengkhom \\ Department of Computer Science \& Engineering, Amity University Uttar Pradesh, Noida, India \\ Email: ymonasha4@gmail.com \\ Pradeep Kumar Singh \\ Department of Computer Science \& Engineering, Amity University Uttar Pradesh, Noida, India \\ Email: pksingh16@gmail.com
}

\begin{abstract}
As Watermarking have been considered as an emerging technique for copyright protection, data security and protection of ownership, several techniques and algorithms have been developed and created either in spatial domain or frequency domain mainly to achieve the properties of digital watermarking like robustness, imperceptibility, fidelity, etc. It is also found that the frequency domain techniques provides a better solution in obtaining these properties than the spatial domain. So, most researchers have used this domain in developing a good watermarking scheme for achieving robustness and other important properties of digital watermarking against all kinds of intentional and unintentional attacks. The attacks may include image processing attacks like compression, frame dropping, piracy, geometric distortions, loss of quality, etc. So, utmost importance must be given on how to create a scheme which can achieve robustness against all these attacks at the same time. The medium for watermarking is chosen as video because of its vast future scope So, in this paper, a thorough research on the various techniques available in watermarking based on frequency domain has been done to find out a secure technique that can withstand any kinds of attacks in a digital video.
\end{abstract}

Index Terms-Watermarking, frequency domainDiscrete Wavelet Transform (DWT), Discrete Fourier Transform (DFT), Discrete Cosine Transform (DCT), digital videos.

\section{INTRODUCTION}

With the advancement of technologies, the usage of multimedia content (like image, audio, and video) has increased up to a high level. There are thousands of uploads and downloads happening every day. Some may use it just to take knowledge but some other may manipulate the content and claim it as theirs. So, utmost importance must be given to the security of ownership. There have been several work done on this area and some have achieved a lot. Watermarking algorithm just embeds a symbol, an image, video or anything in a content so that it may be difficult to use by others without permission from the real owner. There are several techniques involved in watermarking but the important factors that should be kept in mind to achieve a good watermarking technique are robustness to any kinds of attacks, imperceptibility, increase performance without destroying the real content, increase fidelity aspects, key restrictions, tamper resistance and should give good performance in maintaining real time applications .It is somewhat similar to steganography as both of them hide messages inside a digital signal. The only difference is that a watermarking hide messages which are related to the actual content of the digital signal. But in steganography, there is no need to be similarity between messages and the digital signal. In some applications like forensic watermarking, it is used to trace any 'leakage' of content. Collusion attack is the most powerful attack against this type of watermarking. This attack involves multiple collaborated attackers whose motive is to remove the watermark. When it comes to watermarking applications, the algorithms must satisfy better robustness and simplicity to protect against various attacks. Some challenging attacks are rotation, scaling, and translation or RST and they are considered important because the size and orientation of images or videos might change during geometrical transformation attacks and it may become very difficult to detect watermark contents even after slight changes. Digital video watermarking algorithms mainly works in the embedding domain, such as the spatial domain or frequency domain, compressed domain, and bit stream domain.

\section{A. Applications of Watermarking}

The different types of applications on watermarking are as follows:

(1) Broadcast monitoring: to monitor if their ads are being broadcast at the time they are paid for and to track when a specific video is being broadcast.

(2) Ownership identification: In order to identify the owner of a specific digital work easily in case of a copyright infringement.

(3) Controlling copying of works: It prevents illegal copying of videos, songs, movies 
There are basically two embedding techniques involved in watermarking, they are watermarking in spatial domain and in frequency domain. Spatial domain watermark are created by just altering some of the pixels in the media. It is easier to implement but cannot achieve robustness. Whereas, Frequency domain watermarks are obtained by modifying the transform coefficients of the frames contain in videos.

\section{TECHNIQUES IN FREQUENCY DOMAIN}

Some techniques under this domain are DWT (Domain Wavelet Transform), DCT (Domain Cosine Transform) and DFT (Discrete Fourier Transform):

(i) DISCRETE WAVELET TRANSFORM: It is the most widely used as it is robust to any attacks. DWT is a method that decomposes a signal into high and low frequency. The DWT decompose an image into a lower resolution approximation image (LL) as well as horizontal (HL), vertical (LH) and diagonal $(\mathrm{HH})$ detail components.

(ii) DISCRETE COSINE TRANSFORM: It is a method that separates image parts according to importance based on some imaging visual quality. The DCT is a very popular transform function used in signal processing. It transforms a signal from spatial domain to frequency domain. . The 2D-DCT transform and its inverse manner can be expressed as follows:

$$
\begin{gathered}
\mathrm{F}(\mathrm{u}, \mathrm{v})=\alpha(\mathrm{u}) \alpha(\mathrm{v}) \sum \sum \mathrm{f}(\mathrm{x}, \mathrm{y}) \cos [(2 \mathrm{x}+1) \\
\pi \mathrm{u} / 2 \mathrm{M}] \cos [(2 \mathrm{y}+1) \pi \mathrm{u} / 2 \mathrm{~N}]
\end{gathered}
$$

Where, $\mathrm{u}=0,1 \ldots \mathrm{M}-1$ and $\mathrm{v}=0,1 \ldots \mathrm{N}-1$.

$$
\mathrm{f}(\mathrm{x}, \mathrm{y})=\sum \sum_{\pi \mathrm{u} / 2 \mathrm{M}] \cos [(2 \mathrm{y}+1) \pi \mathrm{u} / 2 \mathrm{~N}]} \alpha(\mathrm{u}) \alpha(\mathrm{u}) \mathrm{F}(\mathrm{v}) \cos [(2)
$$

Where, $x=0,1, \ldots, M-1$ and $y=0,1, \ldots, N-1$.

(iii) DISCRETE FOURIER TRANSFORM: The Discrete Fourier Transform (DFT) of a real image is conjugate symmetric, resulting in a symmetric DFT spectrum. Because of this property, the popularity of DFT-based watermarking has increased in the last few years [5].The Fourier Transform is used to decompose an image into its sine and cosine components.

\section{LITERATURE REVIEW}

During Literature survey, I have searched ACM digital library, IEEE explorer and some journals and downloaded around 50 papers. From which the most relevant ones have been taken into account and remaining were discarded. We have adopted the same approach as considered by Singh et al. [34-37] during their survey. The detailed analyses have been mentioned in Table 1 .
Watermarks that can be embedded in transform domain are based on techniques like the Discrete Cosine Transform (DCT) or Discrete Wavelet Transform (DWT) [1]. Many works have been done already that uses each of these techniques to increase robustness. All of these techniques have their own advantages and disadvantages. They are:

- DWT-based approach enable good spatial localization and have multiresolution characteristics, which are similar to the human visual system. In addition, this approach shows robustness to low-pass and median filtering. However, it is not robust to geometric transformations [2].

- The DCT approach is very robust to JPEG compression, since JPEG compression itself uses DCT. However, DCT methods lack resistance to strong geometric. In terms of property, the DCT has a strong energy compaction property and most of the signal information tends to be concentrated in a few low-frequency components of the DCT. [3].

The DFT approach has one advantage in comparison with the spatial domain methods [4]. First, it is translation invariant and rotation resistant, which translates to strong robustness to geometric attacks. FFT watermarking methods are developed to create robust watermarking schemes resistant to the degradation attacks [5].The use of DCT along with PCA Based Image Perceptual Hashing Algorithm which aim at developing and exploring a robust algorithm has been proposed by Z. Jie [6]. KB. Raja et al. [7] have proposed a new technique of steganography that consist of a combination of Least Significant Bit(LSB), DCT, and some compression techniques for enhancing the security of packages being transferred. Several other combinations are wavelet domain along with scan based encryption method has been used to increase speed and security and it was proposed by M. Sharma et al. [8]. YY. Lee et al. [9] have proposed a technique for watermarking in video using multi bit. However, this method is undesirable and needs high complexity in computation. Also it is found that it is robust to attacks like collusion attacks, geometric attacks and compression. E. Ganic et al. [10] has used low and high frequency bands to embed multiple watermarks in order to show that the watermark embedded in lower frequencies is robust to one set of attacks, and the watermark embedded in higher frequencies is robust to a different set of attacks. So, A. Hu et al. [11] suggested that in order to have good performance in both invisibility and robustness, it is better to use a blind watermarking algorithm based on DFT and DWT. S. Zheng et al. [12] have proposed a new algorithm to protect against RSTinvariant by embedding and detecting watermark based on DFT domain which considers texture characteristics and wedge curves. Results show that this scheme is invariant to geometric attacks. Further, the combination of DFT with Radon transform to achieved robustness 
against video compression and geometric transformations was introduced by Y. Liu et al. [13]. The algorithm could keep the fidelity of the watermarked video and also it was simple. The technique to counteract against temporal de synchronization is mentioned by J. Hou et al. [14] using adaptive watermarking frame selection. For this, S.Baudry et al. [15] have proposed a method to find out whether any other piece of information could also be exploited by this attack. To come up with a solution, they took reference of a non-blind video watermarking system for a specific video to show that the extra watermarked information could be used in a fingerprint-based registration framework. The advantage of this strategy as compared with conventional fingerprint-based techniques are accuracy and no additional storage overhead. M.Schlauweg et al. [16] have proposed an approach that is highly robust to lossy image compression. It showed that warping objects geometrically could be used for property rights protection by embedding information into images imperceptibly. This method support better quality, scalability, flipping and is found to be more secure than other schemes proposed. B. G. Mobasseri et al. [17] have proposed a new watermarking algorithm of MPEG-2 streams which are fragile and support large capacity. Results showed that the watermarked video was resistant to any watermark detection attempts and other kinds of forgery attacks. L. Coria et al. [18] proposed based on Spread Spectrum category which also uses the above mentioned technique. This approach helped in de correlating the frames of videos which yields independent signals and reduce the level of distortion caused by watermark. However the main aim of watermarking is to embed in low cost, but the use of this systems could cost a lot in terms of installation, up gradation and maintenance. So, the work of I.K. Kang et al. [19] proposes a high resolution watermark MPEG-2 video contents in real time system. This work mainly point out the issues that may face while embedding a high resolution watermark video in personal computers as we all know the goal of watermark is to protect against any attacks and achieve robustness. The proposed algorithm is faster and robust as they have used the concept of human visual system (HVS). Nowadays some researchers tries to embed watermark in this movement. However, a lot of issues that comes up while taking up this approach must be kept in mind. Some issues are flickering and motion mismatch if watermarking is embedded without considering motion in frame-by-frame video. For this a better framework was provided by Motion compensated temporal filtering (MCTF) which takes into account motion of object. However, the use of this MCTF depends on the video types whether it is the motion or the texture characteristics and needs to be performed on different domains. D. Bhowmik et al. [20] proposed an improve scheme for video watermarking schemes by using $2 \mathrm{D}+\mathrm{t}+2 \mathrm{D}$ framework which is motion compensated. The proposed framework is better in terms of shielding against embedding distortion and flickering compared to other existing frame-by-frame domain video watermarking techniques in terms of robustness and performance for motion based watermarking approaches in videos achieving robustness in image watermarking. But it seems to perform poorly in terms of robustness for attacks related to video processing like de synchronization, collusion, compression etc. So, a method to enhance security in watermarking using a private key of the owner have been discussed by $U$. Mukhopadhyay et al. in [21]. There has been also an increase advent in the production of animation, games, $\mathrm{TV}$, etc. which leads to the reuse of 3D motion capture (Mocap) commercially and may raise issues related to copyright. P. Agarwal et al. [22] have proposed an improvise method to protect the content of Mocap through the use of a substitutive blind watermarking technique. Another method to protect volume data through the use of grey-level watermarking was proposed by W. Liu et al. in [23]. This technique is based on 3DDWT, 3D-DCT and spread-spectrum. Their main goal was not only to make the watermark invisible but also to protect against any kinds of attacks like filtering, noise addition, etc. D.Kirovski et al. [24] have proposed a new method that combines watermarking and fingerprinting together to make a dual system. These keys cannot recreate any data when it is obtained by a third party but it seems that the detection key if found may lead to easy access of data by any person. The proposed scheme tries to limit this kind of attacks. Although it is easy to embed watermarks in all the frames similarly, it could be easily detected by any techniques like frame averaging. Also, selecting the frames randomly may expose it more to attacks like frame dropping. SN. Mali et al. [25] has proposed an approach that is use to select a frame for embedding watermarks in a scene change algorithm. Since independent watermarks and motionless region can cause problems, a method was employed using principal component analysis (PCA) and DWT by S.A.K. Mostafa et al. [26]. The scheme is found to be robust and imperceptible to attacks like histogram equalization, JPEG and MPEG coding etc. In this scheme, the watermark is created using PCA and embedded in the LL and $\mathrm{HH}$ components of DWT. In continuation to scene based watermarking and more techniques in transform domain, N. Leelavathy et al. [27] have proposed a technique for video watermarking by combining Discrete Multiwavelet Transform (DMWT) with Quantization Index Modulation (QIM) orthogonality. The proposed method is found to be robust against attacks like averaging, frame dropping, swapping, etc. K. Patel et al. [28] uses a technique to remove the difference among frames from consecutive frames But it cannot identify frames with similar intensity distribution. These drawbacks was overcome through the introduction of a clustering-based detection scheme. Some researchers based their work on optimization technique like Genetic algorithm (GA) and neural networks. P. Chan et al. [29] employed GA in their approach to optimize the performance of their watermarking technique and also to find the best technique in transformation domain. SV. Patel et al. [30] have proposed an algorithm based on DWT for a video watermarking scheme. Experiments 
shows that it is robust to video watermarking attacks like lossy compression, frame averaging, noise addition and frame dropping. The introduction of classification system based on Artificial Neural Network (ANN) by M. El'arbi et al. [31] has done a good job in selecting the transformation method which is best for embedding process. Experiments shows that the selected transformation technique increases the quality of video as well as show robustness against geometric attacks. To prevent piracy of digital media, N.K. Dubey et al. [32] have proposed a method using additive spread spectrum and DCT. The method keep track of piracy actions by embedding a payload or watermarking consisting of a time stamp in the video content. Results proved that the watermark is invisible, in real time and robust against such attacks. Apart from combining two or more techniques, some researchers uses even more than two techniques to enhance the watermarking scheme. This can be referred in [33]. The proposed scheme uses a combination of DCT, DWT and SVD. The SVD or singular values has been used to embed watermark in the middle and high frequency sub bands in the coefficients of DCT and DWT. The insertion process have been controlled using peak signal to noise ratio and mean square error. Results showed that the scheme is imperceptible and a maintenance of a good quality of video could also be observed.

Singh et al. [38], proposed a novel digital watermarking techniques against the geometric attacks in context to images.

Table 1. Analysis of Digital Watermarking in Frequency Domain Techniques

\begin{tabular}{|c|c|c|c|c|c|}
\hline $\begin{array}{l}\text { Paper ID \& } \\
\text { References }\end{array}$ & Objective & Authors & Source \& Year & Major Findings & Limitations \\
\hline $\begin{array}{c}1 . \\
{[9]}\end{array}$ & $\begin{array}{l}\text { Watermarking in } \\
\text { video using multi bit. }\end{array}$ & YY. Lee et al. & Springer, 2004 & $\begin{array}{l}\text { Using multi bit } \\
\text { technique makes the } \\
\text { method robust to attacks } \\
\text { like collusion attacks, } \\
\text { geometric attacks and } \\
\text { compression. }\end{array}$ & $\begin{array}{l}\text { This method is } \\
\text { undesirable and needs } \\
\text { high complexity in } \\
\text { computation. }\end{array}$ \\
\hline $\begin{array}{c}2 . \\
{[17]}\end{array}$ & $\begin{array}{l}\text { To develop an MPEG- } \\
2 \text { streams using VLC } \\
\text { Mapping which are } \\
\text { fragile and also } \\
\text { support large capacity. }\end{array}$ & $\begin{array}{l}\text { B. G. Mobasseri } \\
\text { et al. }\end{array}$ & $\begin{array}{l}\text { MM\&Sec, } \\
2005\end{array}$ & $\begin{array}{l}\text { Watermarked video is } \\
\text { resistant to any } \\
\text { watermark detection } \\
\text { attempts and other kinds } \\
\text { of forgery attacks }\end{array}$ & $\begin{array}{l}\text { The results obtained } \\
\text { were only a preliminary } \\
\text { part and it needs more } \\
\text { in-depth testing to obtain } \\
\text { a full length MPEG-2 } \\
\text { stream. }\end{array}$ \\
\hline $\begin{array}{c}4 . \\
{[18]}\end{array}$ & $\begin{array}{l}\text { Use of code words } \\
\text { based on Spread } \\
\text { Spectrum order to } \\
\text { secure fidelity and } \\
\text { robustness of the } \\
\text { watermark }\end{array}$ & L. Coria et al. & DRM, 2006 & $\begin{array}{l}\text { This approach helped in } \\
\text { de correlating the } \\
\text { frames of videos which } \\
\text { yields independent } \\
\text { signals and reduce the } \\
\text { level of distortion } \\
\text { caused by watermark. }\end{array}$ & $\begin{array}{l}\text { Costly installation, up } \\
\text { gradation and } \\
\text { maintenance. }\end{array}$ \\
\hline $\begin{array}{c}5 . \\
{[31]}\end{array}$ & $\begin{array}{l}\text { To use multi- } \\
\text { resolution motion } \\
\text { estimation and neural } \\
\text { network to create a } \\
\text { watermarking scheme. }\end{array}$ & M. El'arbi et al. & IEEE, 2006 & $\begin{array}{l}\text { Neural network is used } \\
\text { to maintain the } \\
\text { relationship between the } \\
\text { coefficients of a block } \\
\text { of image. }\end{array}$ & $\begin{array}{l}\text { The proposed scheme } \\
\text { has not been } \\
\text { experimented to all } \\
\text { kinds of attacks. }\end{array}$ \\
\hline $\begin{array}{c}7 . \\
{[23]}\end{array}$ & $\begin{array}{l}\text { To make the } \\
\text { watermark invisible } \\
\text { and also to protect } \\
\text { against any kinds of } \\
\text { attacks like filtering, } \\
\text { noise addition, etc. }\end{array}$ & W. Liu et al. & ICIS, 2009 & $\begin{array}{l}\text { The MSB is embedded } \\
\text { in the low frequency } \\
\text { components of host data } \\
\text { to increase the } \\
\text { robustness. }\end{array}$ & $\begin{array}{l}\text { Original volume data } \\
\text { and pseudo random } \\
\text { sequence used in } \\
\text { embedding process is } \\
\text { required again in the } \\
\text { extraction process. }\end{array}$ \\
\hline $\begin{array}{c}8 . \\
{[26]}\end{array}$ & $\begin{array}{l}\text { To create a robust and } \\
\text { imperceptible } \\
\text { watermarking scheme } \\
\text { based on PCA and } \\
\text { DWT. }\end{array}$ & $\begin{array}{l}\text { S.A.K Mostafa et } \\
\text { al. }\end{array}$ & IJCSNS, 2009 & $\begin{array}{l}\text { The watermarks is } \\
\text { embedded in the LL and } \\
\text { HH coefficients of } \\
\text { DWT using different } \\
\text { logic with the help of } \\
\text { PCA. }\end{array}$ & $\begin{array}{l}\text { The scheme is not } \\
\text { overall effective to all } \\
\text { the attacks so a suitable } \\
\text { wavelet technique needs } \\
\text { to be find to enhance } \\
\text { robustness and } \\
\text { imperceptibility. }\end{array}$ \\
\hline
\end{tabular}




\begin{tabular}{|c|c|c|c|c|c|}
\hline $\begin{array}{c}9 . \\
{[13]}\end{array}$ & $\begin{array}{lr}\text { To achieve robustness } \\
\text { against } & \text { video } \\
\text { compression } & \text { and } \\
\text { geometric } & \\
\text { transformations } & \end{array}$ & Y. Liu et al. & $\begin{array}{l}\text { Signal Processing, } \\
2010\end{array}$ & $\begin{array}{l}\text { The algorithm could } \\
\text { keep the fidelity of the } \\
\text { watermarked video and } \\
\text { also it was simple. }\end{array}$ & $\begin{array}{l}\text { This method is used only } \\
\text { against geometric } \\
\text { attacks. }\end{array}$ \\
\hline $\begin{array}{l}10 . \\
{[1]}\end{array}$ & $\begin{array}{l}\text { To sorvey the } \\
\text { effectiveness of } \\
\text { various frequency and } \\
\text { wavelet domain tech- } \\
\text { niques. }\end{array}$ & D.Arya & IJSER, 2010 & $\begin{array}{l}\text { A comparison among } \\
\text { different techniques } \\
\text { have been done based } \\
\text { on DWT and DFT. }\end{array}$ & $\begin{array}{l}\text { Other options } \\
\text { techniques were not } \\
\text { mentioned. }\end{array}$ \\
\hline $\begin{array}{c}11 . \\
{[19]}\end{array}$ & $\begin{array}{l}\text { To point out the issues } \\
\text { that may face while } \\
\text { embedding a high } \\
\text { resolution watermark } \\
\text { video. }\end{array}$ & I.K. Kang et al. & $\begin{array}{l}\text { MM \& Sec, } \\
2010\end{array}$ & $\begin{array}{l}\text { The use of human visual } \\
\text { system (HVS) concept } \\
\text { makes this scheme } \\
\text { faster and robust. }\end{array}$ & $\begin{array}{l}\text { The scheme could not } \\
\text { support image } \\
\text { processing or geometric } \\
\text { attacks. }\end{array}$ \\
\hline $\begin{array}{c}12 . \\
{[20]}\end{array}$ & $\begin{array}{l}\text { To compensate video } \\
\text { watermarking using } \\
2 \mathrm{D}+\mathrm{t}+2 \mathrm{D} \text { framework. }\end{array}$ & $\begin{array}{l}\text { D. Bhowmik et } \\
\text { al. }\end{array}$ & $\begin{array}{l}\text { MM \& Sec, } \\
2010\end{array}$ & $\begin{array}{l}\text { The framework is better } \\
\text { in terms of shielding } \\
\text { against embedding } \\
\text { distortion and flickering } \\
\text { compared to other } \\
\text { techniques. }\end{array}$ & $\begin{array}{l}\text { Perform poorly in terms } \\
\text { of robustness for attacks } \\
\text { like de synchronization, } \\
\text { collusion, compression, } \\
\text { etc. }\end{array}$ \\
\hline $\begin{array}{c}13 . \\
{[30]}\end{array}$ & $\begin{array}{l}\text { To make the algorithm } \\
\text { robust against certain } \\
\text { attacks and improve } \\
\text { the quality of video } \\
\text { using GA, }\end{array}$ & S.V.Patel et al. & NCRTET, 2011 & $\begin{array}{l}\text { The video is converted } \\
\text { into DWT and the } \\
\text { watermark is embedded } \\
\text { into its mid frequency } \\
\text { after dividing into } 8 \\
\text { bits. }\end{array}$ & $\begin{array}{l}\text { The scheme is robust } \\
\text { only to few attacks. }\end{array}$ \\
\hline $\begin{array}{c}14 . \\
{[21]}\end{array}$ & $\begin{array}{l}\text { To enhance security in } \\
\text { watermarking using a } \\
\text { private key of the } \\
\text { owner. }\end{array}$ & $\begin{array}{l}\text { U. } \\
\text { Mukhopadhyay } \\
\text { et al. }\end{array}$ & $\begin{array}{l}\text { CCSEIT, } \\
2012\end{array}$ & $\begin{array}{l}\text { This scheme focus on } \\
\text { the fact that without } \\
\text { using the owner's key it } \\
\text { will be hard to decrypt } \\
\text { the data which leads to } \\
\text { security enhancement. }\end{array}$ & $\begin{array}{l}\text { The algorithm works } \\
\text { only in grayscale videos } \\
\text { and the choice of keys is } \\
\text { limited. }\end{array}$ \\
\hline $\begin{array}{c}15 . \\
{[27]}\end{array}$ & $\begin{array}{lr}\text { To use Multiwavelet } \\
\text { technique to embed } \\
\text { watermark } \\
\text { prevent from some } \\
\text { attacks like frame } \\
\text { dropping. }\end{array}$ & $\begin{array}{l}\text { N. Leelavathy et } \\
\text { al. }\end{array}$ & IJMSE, 2012 & $\begin{array}{l}\text { Mixed up watermarks } \\
\text { are created using secret } \\
\text { keys and it is embedded } \\
\text { in the uncompressed } \\
\text { domain of the } \\
\text { motionless video. }\end{array}$ & $\begin{array}{l}\text { More } h \text { improvement is } \\
\text { needed in the analysis of } \\
\text { a scene which is in } \\
\text { gradual change. }\end{array}$ \\
\hline $\begin{array}{l}16 . \\
{[4]}\end{array}$ & $\begin{array}{l}\text { To use DWT with } \\
\text { PCA to create a hybrid } \\
\text { digital watermarking } \\
\text { scheme. }\end{array}$ & S.A. Patil et al. & IOSRJEN, 2013 & $\begin{array}{l}\text { The relation between } \\
\text { the coefficients of DWT } \\
\text { is reduce using the } \\
\text { PCA. }\end{array}$ & $\begin{array}{l}\text { The NC or Normalized } \\
\text { Coefficient changes for } \\
\text { each kinds of attacks. }\end{array}$ \\
\hline $\begin{array}{l}17 . \\
{[5]}\end{array}$ & $\begin{array}{l}\text { To create a lossless } \\
\text { information hiding } \\
\text { scheme using DWT. }\end{array}$ & P. Patil et al. & IJEAT, 2013 & $\begin{array}{l}\text { The secret information } \\
\text { is embedded in the } \\
\text { middle high frequency } \\
\text { range of DWT } \\
\text { coefficients. }\end{array}$ & $\begin{array}{l}\text { It focus mainly on data } \\
\text { hiding and not on } \\
\text { prevention of attacks. }\end{array}$ \\
\hline $\begin{array}{c}18 . \\
{[25]}\end{array}$ & $\begin{array}{l}\text { To select a frame for } \\
\text { embedding } \\
\text { watermarks in a scene } \\
\text { change algorithm }\end{array}$ & SN. Mali et al. & $\begin{array}{l}\text { TECHNOVISION, } \\
2014\end{array}$ & $\begin{array}{l}\text { The use of SCD models } \\
\text { can help in developing a } \\
\text { systematic procedure } \\
\text { based on mathematical } \\
\text { models. }\end{array}$ & $\begin{array}{l}\text { The scheme is yet to } \\
\text { cover motion of objects, } \\
\text { object shapes and the } \\
\text { ability to adjust with } \\
\text { other SCD techniques. }\end{array}$ \\
\hline $\begin{array}{c}19 . \\
{[14]}\end{array}$ & $\begin{array}{l}\text { To use spread } \\
\text { spectrum in DCT to } \\
\text { achieve robustness } \\
\text { against attacks like } \\
\text { MPEG Compression. }\end{array}$ & J. Hou et al. & ACM, 2014 & $\begin{array}{l}\text { The watermark is } \\
\text { embedded in the blue } \\
\text { channel and that a DA- } \\
\mathrm{AD} \text { environment is used } \\
\text { to measure } \\
\text { performance. It is robust } \\
\text { and invisible. }\end{array}$ & $\begin{array}{l}\text { The scheme is bit } \\
\text { lengthy and more } \\
\text { conversions is required. }\end{array}$ \\
\hline $\begin{array}{c}20 . \\
{[32]}\end{array}$ & $\begin{array}{l}\text { To prevent piracy by } \\
\text { embedding a payload } \\
\text { in video content. }\end{array}$ & $\begin{array}{l}\text { N. K. Dubey et } \\
\text { al. }\end{array}$ & IJSIA, 2015 & $\begin{array}{l}\text { The watermark has been } \\
\text { embedded in the } \\
\text { luminance region which } \\
\text { is less sensitive to color. }\end{array}$ & $\begin{array}{l}\text { It has been tested only } \\
\text { against } \\
\text { distortions. }\end{array}$ \\
\hline $\begin{array}{c}21 . \\
\text { [33] }\end{array}$ & $\begin{array}{l}\text { To increase the } \\
\text { imperceptibility of a } \\
\text { watermarking scheme } \\
\text { in videos using DCT, } \\
\text { DWT and SVD. }\end{array}$ & C. N. Sujatha & IJSETR, 2015 & $\begin{array}{l}\text { The watermark is } \\
\text { embedded using SVD in } \\
\text { middle frequency band } \\
\text { of DCT and high } \\
\text { frequency bands of } \\
\text { DWT coefficients. It is } \\
\text { imperceptible and } \\
\text { maintains good quality } \\
\text { of the video content. }\end{array}$ & $\begin{array}{lr}\text { It has not been } \\
\text { experimented } & \text { for } \\
\text { preventing attacks like } \\
\text { frame } & \text { dropping, } \\
\text { compression. }\end{array}$ \\
\hline
\end{tabular}




\section{CONCLUSIONS}

As achieving robustness and other properties have been a main concern for achieving a successful digital watermarking scheme in videos, several researchers have experimented on various techniques available based on frequency domain. The combination of these techniques along with other techniques from different domain helped in enhancing the robustness. Some techniques could easily achieve robustness against certain attacks while some other on different attacks like geometric distortions, image processing attacks. But a scheme that could prevent every types of attacks at the same time was hard to develop.

\section{REFERENCES}

[1] D. Arya, "A survey on frequency and wavelet domain digital watermarking techniques", International Journal of Scientific \& Engineering Research, Vol.1, No. 2, pp. 286292, 2010.

[2] W. Y. Chen , H. S. Yuan, “ Digital Watermarking using DCT transformation", National Chin-Yi University Library, China, pp. 173-184, 2012.

[3] A.Poljicak, L. Mandic, D. Agic, "Discrete Fourier transform-based watermarking method with an optimal implementation radius", Journal of Electronic Imaging, Vol.20, No.3, pp.3001-3009, 2011.

[4] S.A. Patil, N. Srivastava, "Digital video watermarking using Dwt and Pca", IOSR Journal of Engineering, Vol.3, No. 11, pp. 45-49, 2013.

[5] P. Patil, DS. Bormane, "DWT-based invisible watermarking technique for Digital Images", International journal of Engineering and Advanced Technology, Vol. 2, No. 4, pp.603-605, 2013.

[6] Z. Jie, "A Novel Block-DCT and PCA Based Image Perceptual Hashing Algorithm", http://arxiv.org/abs/1306.4079, access on 24/02/2015.

[7] KB. Raja, CR. Chowdary, KR. Venugopal, and LM. Patnaik, "A secure image steganography using LSB, DCT, and compression techniques on raw images", published in Proceedings of IEEE 3rd International Conference on Intelligent Sensing and Information Processing, Bangalore, India, pp. 170-176, ,2005.

[8] M. Sharma, A. Tiwari, "A Hybrid technique of Video Watermarking in Wavelet domain and Scan based Encryption Method", IJEDR, Vol.2, No. 3, pp. 3220-3224, 2014.

[9] YY. Lee, HS. Jung, S. Lee, "Multi-bit Video Watermarking Based on 3D DFT Using Perceptual Models", Springer, Vol. 2939, pp. 301-315, 2004.

[10] E.Ganic, S. D. Dexter, A.M.Eskicioglu, "Embedding Multiple Watermarks in the DFT Domain Using Low and High Frequency Bands", SPIE, Vol. 5681, pp. 175-184, USA, 2005.

[11] A.Hu, N. Chen, "A Blind Watermarking Algorithm for Color Image Based on Wavelet Transform and Fourier Transform", published in the proceedings of IEEE 9th International Conference for Young Computer Scientists, ICYCS, Hunan, pp. 1453-1458, 2008.

[12] S. Zheng, Y. Zhu, X. Wang, "A new RST-invariant watermarking scheme based on texture features", published in Proceedings of the 1st international conference on Forensic applications and techniques in telecommunications, information, and multimedia and workshop, e-Forensics '08, Article No. 23, Belgium, 2008.

[13] Y. Liu, J. Zhao, "A new video watermarking algorithm based on 1D DFT and Radon transform", Signal Processing, Vol.90, No. 2, pp. 626-639, Canada, 2010.

[14] J. Hou, J. Park, D. Kim, S.Nam, H.Lee, "Robust Video Watermarking for MPEG Compression and DA-AD Conversion", published in the Proceedings of the 1st international workshop on Information hiding and its criteria for evaluation, IWIHC '14, pp.2-8,USA, 2014.

[15] S.Baudry, C. Sevigne, "Frame-accurate temporal registration for non-blind video watermarking", published in Proceedings of the on Multimedia and security, MM\&Sec '12, pp. 19-26, ACM New York, 2012.

[16] M. Schlauweg, D. Pröfrock, B. Zeibich, E.Müller, "Dual watermarking for protection of rightful ownership and secure image authentication", published in Proceedings of the 4th ACM international workshop on Contents protection and security, MCPS '06, pp. 59 - 66, USA, 2006.

[17] BG. Mobasseri, MP. Marcinak, "Watermarking of MPEG2 video in compressed domain using VLC mapping", Published in Proceedings of the 7th workshop on Multimedia and security, pp. 91-94, NY, USA, 2005.

[18] L. Coria, P. Nasiopoulos, R.Ward, "A robust contentdependent algorithm for video watermarking", Published in Proceedings of the ACM workshop on Digital rights management, DRM '06, pp. 97 - 10 , NY, USA, 2006.

[19] IK. Kang, DH. Im, HK. Lee, YH. Suh, "Implementation of real-time watermarking scheme for high-quality video", published in the proceedings of the 8th workshop on Multimedia and security, pp.124-129, Geneva, 2006.

[20] D. Bhowmik, C. Abhayaratne, "Video watermarking using motion compensated $2 \mathrm{D}+\mathrm{t}+2 \mathrm{D}$ filtering", Published in Proceedings of the 12th ACM workshop on Multimedia and security, MM\&Sec '10, pp. 127-136, NY, USA, 2010.

[21] U. Mukhopadhyay, S. Sinha, P. Ghosh, R. Ghosh, DK. Kole, A. Chakraborty, "Enhancing the security of digital Video Watermarking using watermark encryption", Published in Proceedings of the Second International Conference on Computational Science, Engineering and Information Technology, pp. 145-150, 2012.

[22] P. Agarwal, K. Adi, B. Prabhakaran, " Robust blind watermarking mechanism for motion data streams", Published in the Proceedings of the 8th workshop on Multimedia and security, MM\&Sec '06, pp. 230-235, 2006.

[23] W.Liu, Zhao, "Digital watermarking for volume data based on 3D-DWT and 3D-DCT", Published in Proceedings of the 2nd International Conference on Interaction Sciences: Information Technology, Culture and Human, pp.352-357, USA, 2009.

[24] D. Kirovski, H. Malvar, Y. Yacobi, "Multimedia content screening using a dual watermarking and fingerprinting system", Published in Proceedings of the tenth ACM international conference on Multimedia, pp. 372-381,2002.

[25] Dr.SN. Mali, C.S. Gosavi, "Frame Selection for Video Watermark Embedding using. Scene Change Detection Algorithm”, Technovision-2014, Vol. 5, No. 4, July, 2014

[26] S.A.K Mostafa, A. S. Tolba, F. M. Abdelkader, H.M. Elhindy, "Video Watermarking Scheme Based on Principal Component Analysis and Wavelet Transform", International Journal of Computer Science and Network Security, IJCSNS, Vol.9 No.8, pp. 45-52, August 2009.

[27] N. Leelavathy, E. V. Prasad and S. Srinivas Kumar, "3D Scene Based Video Watermarking in Discrete Multiwavelet Domain" International Journal of Multidisciplinary Sciences and Engineering, vol.3, No. 7, 
pp. $12-17,2012$

[28] K. Patel, M.Tiwari, J.Singh, "Video Water Marking Using Abrupt Scene Change Detection", International Journal of Computer Technology and Electronics Engineering, IJCTEE, Vol. 1, No. 2, pp-187-190, 2011.

[29] P. Chan, MR. Lyu. "Digital Video Watermarking with a Genetic Algorithm", Published in Proceedings of International Conference on Digital Archives Technologies, ICDAT '05, pp. 139-153, Taiwan, 2005.

[30] SV. Patel, AR. Yadav, "Invisible Digital Video Watermarking Using 4 Level DWT", National Conference on Recent Trends in Engineering \& Technology, pp.1-6, 2011.

[31] M. El'arbi, C. B. Amar and H. Nicolas, "Video Watermarking Based on Neural Networks", In Proceedings of IEEE Multimedia and Expo, pp. 15771580, 2006.

[32] N.K.Dubey, S. Kumar, "An Effective Approach of Distortion-Resistant Video Watermarking for Piracy Deterrence", International Journal of Security and Its Applications, Vol.9, No.1, pp.283-294, 2015.

[33] C. N. Sujatha, P. Satyanarayana , "High Capacity Video Watermarking based on DWT-DCT-SVD", International Journal of Science, Engineering and Technology Research (IJSETR), Vol. 4, No. 2,pp. 245-249, 2015.

[34] Pradeep Kumar Singh, O.P. Sangwan and A. Sharm,a A Systematic Review on Fault Based Mutation Testing Techniques and Tools for Aspect-J Programs, published in $3^{\text {rd }}$ IEEE International Advance Computing Conference, IACC-2013 at AKGEC Ghaziabad, India,22-23,February 2013, IEEE Xplore, pp. 1455-1461, 2013.

[35] P.K. Singh, D. Agarwal, A. Gupta, A Systematic Review on Software Defect Prediction, published in Computing for Sustainable Global Development (INDIACom), IEEE, pp. 1793-97, 2015.

[36] P.K. Singh, Ranjan Panda, O.P. Sangwan, A Critical Analysis on Software Fault Prediction Techniques, published in World Applied Sciences Journal, Vol. 33, No. 3, pp. 371-379, 2015.
[37] Pradeep Kumar Singh, Kritika Verma (2015). An Insight to Soft Computing based Defect Prediction Techniques in Software, International Journal on Modern Education and Computer Science (IJMECS), Hong Kong. Vol. 7, No. 9, pp. 52-58. [ISSN: 2075-0161, ISI Index \& Impact Factor $=0.13]$.

[38] Pradeep Kumar Singh, Anadi Ajay(2015). Novel Digital Image Water Marking Technique Against Geometric Attacks, International Journal on Modern Education and Computer Science (IJMECS), Hong Kong. Vol. 7, No. 8, pp. 61-68. [ISSN: 2075-0161, ISI Index \& Impact Factor $=0.13]$.

\section{Authors' Profiles}

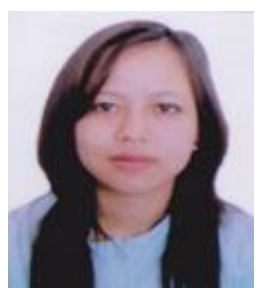

Ms. Monasa Yengkhom is currently pursuing M.Tech degree in Computer Science \& Engineering from Amity University, Noida. Her areas of interests are image processing, Digital watermarking and cloud computing.

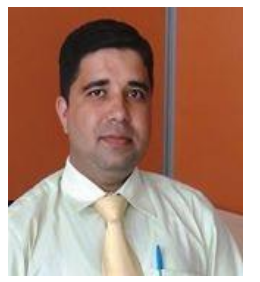

Dr. Pradeep Kumar Singh is an Assistant Professor in Computer Engineering and Engineering Department at the Amity School of Engineering and Technology, Amity University Uttar Pradesh, Noida, India. He is member of ACM, CSI and many professional bodies. $\mathrm{He}$ has published 25 papers in International Conferences and Journals of repute.

How to cite this paper: Monasa Yengkhom, Pradeep Kumar Singh,"An Analysis on Digital Watermarking in Videos based on Frequency Domain Techniques", IJMECS, vol.7, no.12, pp.35-41, 2015.DOI: 10.5815/ijmecs.2015.12.05 